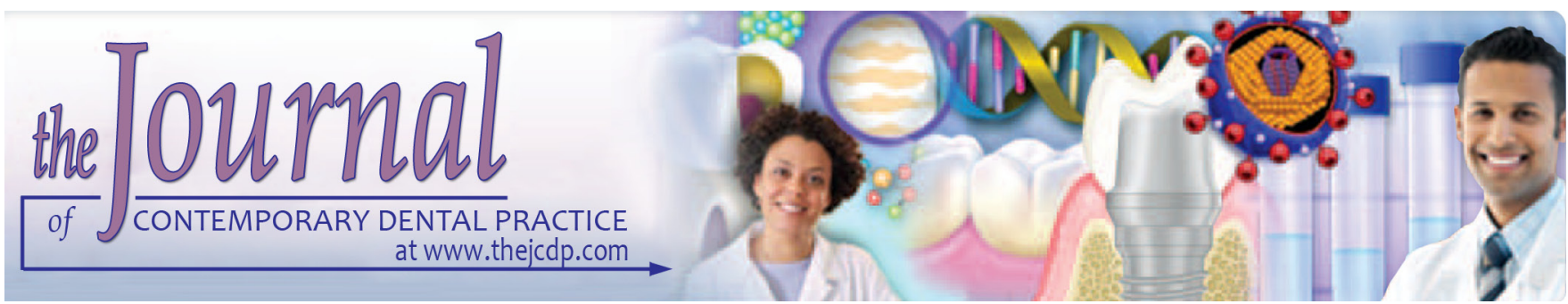

\title{
Primary Diffuse Large B-cell Lymphoma involving the Mandible
}

\author{
${ }^{1}$ Faleh Ali A Alshahrani, ${ }^{2}$ Abdulsalam S Aljabab, ${ }^{3}$ Ibraheem HM Motabi, ${ }^{4}$ Abdullah Alrashed, ${ }^{5}$ Sukumaran Anil
}

\begin{abstract}
Lymphomas of the oral cavity are rare and typically present as intraosseous lesions that are most commonly diffuse large B-cell type. Diffuse large B-cell lymphoma (DLBCL) is an aggressive B-cell lymphoma histologically characterized by diffuse proliferation of large neoplastic B-lymphoid cells with a nuclear size equal to or exceeding normal histiocytic nuclei. $A$ case of DLBCL of the mandible in an 18 years old male patient is presented. This report discusses this rare malignancy, including clinical presentation, histopathologic features, immunologic profile, treatment and prognosis. Though lymphoma of mandible is rare, it must be considered in differential diagnosis of swellings arising in the region.
\end{abstract}

Keywords: B-cell lymphoma, Diffuse large B-cell lymphoma, Intraosseous lymphoma, Mandible, Non-Hodgkin's lymphoma.

How to cite this article: Alshahrani FAA, Aljabab AS, Motabi IHM, Alrashed A, Anil S. Primary Diffuse Large B-cell Lymphoma involving the Mandible. J Contemp Dent Pract 2015;16(10):840-844.

\section{Source of support: Nil}

Conflict of interest: None

\footnotetext{
${ }^{1}$ Department of Oral and Maxillofacial Surgery, King Fahad Medical City, Riyadh, Saudi Arabia

${ }^{2}$ Department of Oral and Maxillofacial Surgery, Head and Neck Surgical Oncology, King Fahad Medical City, Riyadh Saudi Arabia

${ }^{3}$ Department of Adult Hematology and Blood Marrow Transplant, King Fahad Medical City, Riyadh, Saudi Arabia

${ }^{4}$ Department of Radiology, Unit of Neuroradiology, King Fahad Medical City, Riyadh, Saudi Arabia

${ }^{5}$ Department of Dental Health, College of Applied Medical Sciences, King Saud University, Riyadh, Saudi Arabia

Corresponding Author: Faleh Ali A Alshahrani, Board Resident, Department of Oral and Maxillofacial Surgery, King Fahad Medical City, Riyadh, Saudi Arabia, Phone: +966 56 444 4402, e-mail: ksucod@gmail.com
}

\section{INTRODUCTION}

Lymphomas are malignant neoplasms of lymphocytes and their precursor cells. Non-Hodgkin's lymphomas (NHL) are a group of neoplasms that originate from the cells of the lymphoreticular system. ${ }^{1}$ Non-Hodgkin's lymphomas are a heterogeneous group of lymphoproliferative malignancies that are much less predictable than HD and have a far greater predilection to disseminate to extranodal tissues. ${ }^{2}$ They account for less than $5 \%$ of all oral malignancies; lymphomas are the most frequent nonepithelial malignant tumors of the oral cavity and maxillofacial region. In the head and neck region, NHL can occur within soft tissue or bone. The salivary gland, cheek, paranasal sinuses, and gingiva are the most common sites. ${ }^{2,3}$ Jaw involvement of NHL is rare, but among jaw lesions, the maxilla is more frequently involved than the mandible. ${ }^{2,4}$ Non-Hodgkin's lymphomas in the mandible accounts for only $0.6 \%$ of all NHL and the most frequent site of occurrence is the mandibular body. ${ }^{5-8}$

This heterogeneous group of lymphoid neoplasm is characterized by diverse spectrum of clinical and morphological features and prognosis. ${ }^{9}$ Diffuse large B-cell lymphoma (DLBCL) is characterized by diffuse proliferation of large neoplastic B lymphoid cells with nuclear size equal to or exceeding normal macrophage nuclei, or more than twice the size of a normal lymphocyte. ${ }^{10}$ Diffuse large B-cell lymphoma may arise as a primary tumor or as a result of progression and transformation of a less aggressive lymphoma of a lower grade such as lymphocytic, follicular or marginal lymphoma. Based on its morphology, the DLBCL can be centroblastic or immunoblastic. ${ }^{11}$ Centroblastic lymphoma is the most common subtype with better prognosis compared with immunoblastic and anaplastic variants of DLBCL. ${ }^{12} \mathrm{~A}$ case of diffuse large B-cell lymphoma of the mandible in an 18-year-old male patient is reported. 


\section{CASE REPORT}

An 18-year-old male presented to maxillofacial surgery clinic in King Fahad Medical City with swelling of the lower jaw. The patient noticed the swelling for the past 6 months which slowly progressed with pain, and paresthesia in the chin (Fig. 1).

Histopathological examination of the biopsy showed infiltration by atypical lymphocytes. Morphology and immunohistochemistry were strongly suggestive of DLBCL (Fig. 2). The extent of the lesion was analyzed using contrast and coronal computed tomography (CT) examination of the skull (Figs 3 to 5). Magnetic resonance imaging (MRI) was performed to assess the extent of bone marrow infiltration and the soft tissue involvement (Fig. 6).

The complete staging workup did not show involvement of the bone marrow. Computed tomography scan of the chest, abdomen, pelvis and bone marrow biopsy showed no evidence of lymphoma elsewhere. Serologic tests included a complete blood count and chemistry

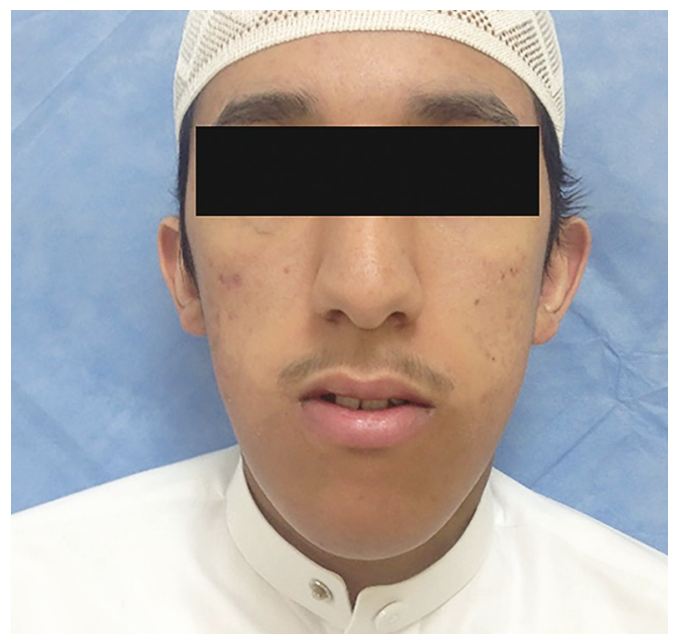

Fig. 1: Photograph of the patient showing the enlargement of the mandible

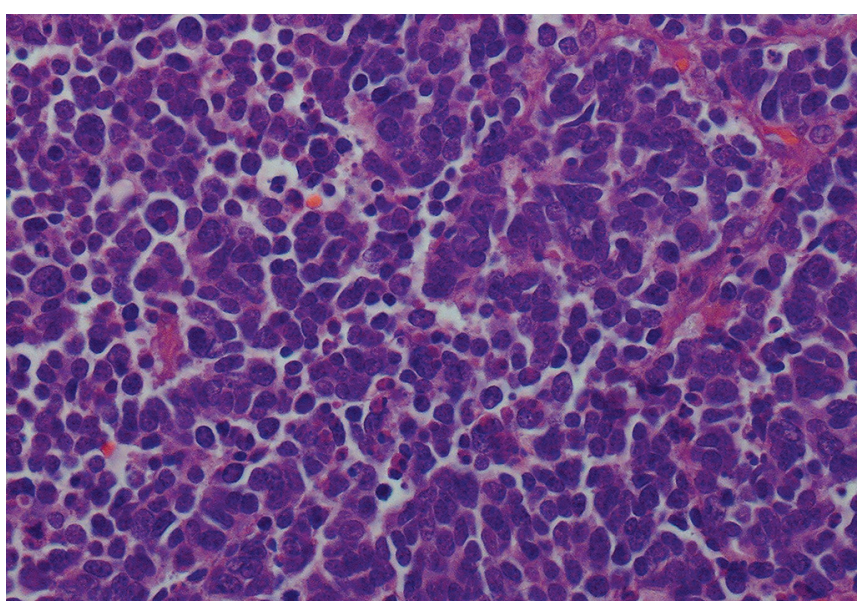

Fig. 2: Histopathologic appearance of the lesion large B-cell lymphoma showing atypical pleomorphic lymphoid cells with a sprinkling of small mature lymphocytes in the background

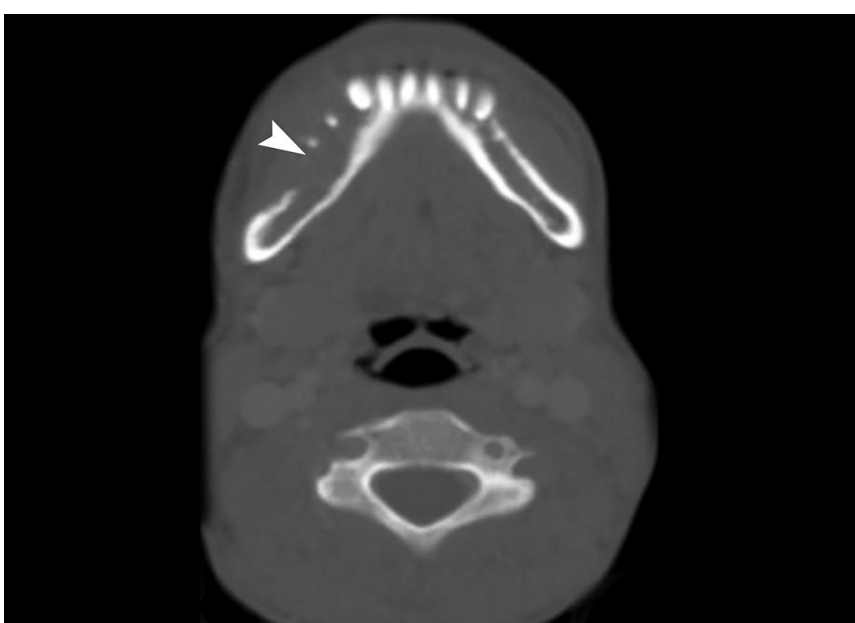

Fig. 3: Axial CT scan bone window shows lytic lesions involving the mandible with mild expansion of the marrow cavity and destruction of the outer cortex

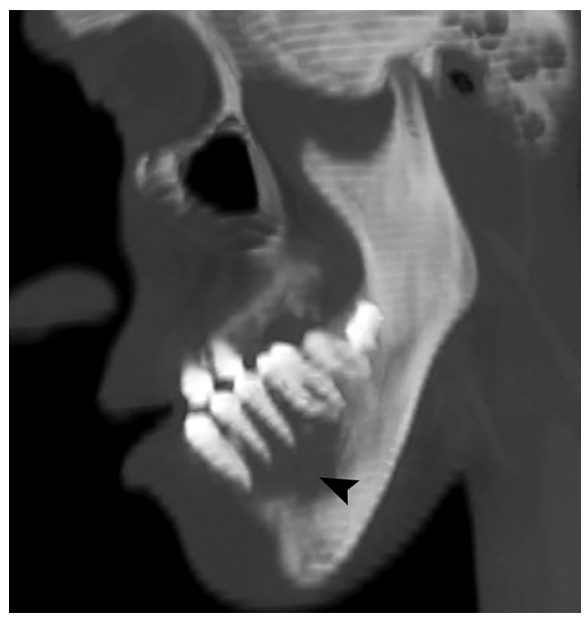

Fig. 4: Sagittal oblique MIP CT scan image shows involvement of the alveolar portion of the right mandible and the adjacent molar and premolars appear floating

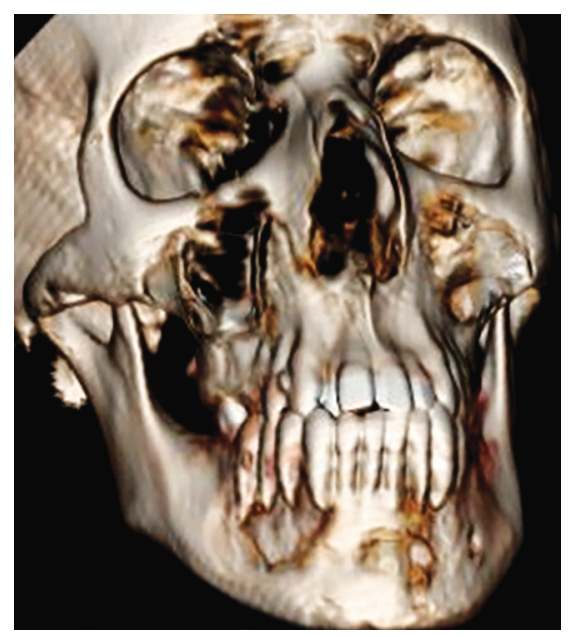

Fig. 5: Three-dimensional CT images show lytic lesions involving the mandible with destruction of the outer cortex

panel, which showed only minor deviations from the normal range for glucose, potassium, and chloride levels, none of which were considered to be associated with this malignancy. 

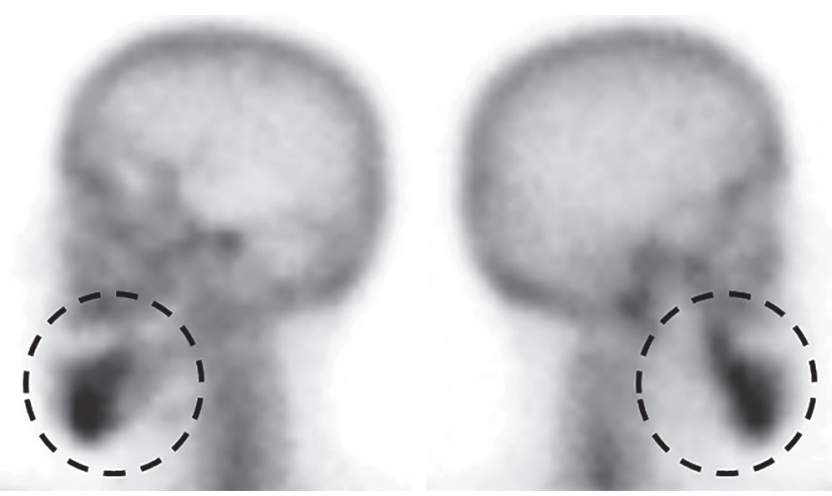

Fig. 6: Bone scan and spot images of the mandible-increased uptake in the mandible extending bilaterally on both sides

Combined treatment was carried out with rituximab and cyclophosphamide, hydroxydaunorubicin, vincristine, and prednisolone (R-CHOP) 4 cycles of chemotherapy according to the $\mathrm{R}-\mathrm{CHOP}$ regimen. After the second cycle of therapy, the clinical response was good with the disappearance of mandibular swelling. Radiotherapy was performed using IFRT 40 GY / 20 Fractions for the upper neck and mandible. Positron emission tomography (PET) scan post chemo showed complete metabolic resolution.

\section{DISCUSSION}

Lymphomas are a group of neoplasms arising in the reticuloendothelial and lymphatic system. ${ }^{8,13}$ There are two major categories: non-Hodgkin's lymphoma and Hodgkin's disease. The head and neck is the second most common site of extranodal lymphomas after the gastrointestinal tract. Among the NHL that occurs in the oral cavity, 15 to $45 \%$ arises in the maxilla. The other locations are the mandible $(8 \%)$, the palatal soft tissue $(8 \%)$ and gingiva $(7 \%)$. Isolated mandibular NHL account for only $0.6 \%$ of all the NHL. ${ }^{14,15}$ Approximately $85 \%$ of NHLs are B-cell lymphomas. ${ }^{15}$ Diffuse large B-cell lymphoma is considered to be the most common subtype of NHL including primary mandibular NHL. ${ }^{16}$

Swelling of the bone is the most frequent clinical presentation, with associated tooth mobility, pain, and neurologic disturbance. Symptoms, such as tooth mobility and pain may lead to an incorrect diagnosis, because these symptoms are often present in common dental diseases. ${ }^{2,5}$ This patient presented with swelling and paresthesia which prompted the clinical diagnosis of a malignant tumor.

Histopathology, immunohistochemistry, immunophenotyping, and genetic studies help to make the diagnosis of NHL. The pattern of involvement and histologic type is important in order to direct a specific regimen of therapy. The cell architecture and histology of bony NHL is indistinguishable from nodal or lymphoid derived lymphomas. They arise from the medullary cavity and manifest as a localized, solitary lesion. ${ }^{17}$ Non-Hodgkin's lymphoma usually expresses pan B-cell markers, such as CD19, CD20, CD75, CD79a, and CD22; but may lack one or more of these. Surface and or cytoplasmic immunoglobulins ( $\operatorname{IgM}>\operatorname{IgG}>\operatorname{IgA}$ ) can be demonstrated in 50 to $75 \%$ of cases. ${ }^{18}$ In the present case, the histopathology showed highly atypical lymphoid cells. Immunophenotyping of peripheral blood lymphocytes by flow cytometry shows a T-cell population (about $68 \%$ of the cells analyzed) with no aberrant loss or aberrant expression of T-cell markers, a B-cell population (about 18\% of the cells analyzed) that is negative for CD5, CD10, with no evidence of surface-light chain restriction.

Radiographicfeatures of DLBCLarenotspecific for diagnosis. Features are usually that of nonspecific osteolysis. There can be diffuse bone destruction, appearing as a solitary defect or resorption of the alveolar bone margin, which resembles periodontitis or a periodontal abscess. ${ }^{19}$ Panoramic films show ill-defined radiolucency of the mandible indicating bone destruction. High resolution CT scans, however, allows detection of minor alterations in radiodensity reflecting the presence of intramedullary lymphomatous infiltration. ${ }^{20}$ Enhancement of regions within the tumor after contrast media administration probably corresponds to areas of high cellularity and viable tumor. ${ }^{21}$ Positron emission tomography scanning is frequently used to define a treatment plan, to determine prognosis, and also to provide a means for surveillance within the post-treatment course. In the case reported, CT of the mandible showed destructive lesions involving the mandible. Computed tomography of neck, chest, abdomen and pelvis showed no other area of involvement. Bone scan showed increased risk tracer uptake in the primary mandibular lesion, but there is no scintigraphic evidence of distant bone metastasis.

Treatment for primary lymphoma of the mandible typically consists of a combination of chemotherapy and radiotherapy. ${ }^{22}$ Surgical approach is limited to obtaining a specimen representative of the lesion and sufficient for a complete histological examination. ${ }^{8}$ Lesions arising in bone are best treated by chemotherapy. Prognosis is excellent in localized disease, whereas disseminated disease seems less favorable. ${ }^{23,24}$ The use of monoclonal CD20 antibody, rituximab, to support chemotherapy has become common in DLBCL therapy. ${ }^{25}$ The present case is being reported for the clinical importance of an excellent prognosis, compared to that portrayed by other mandibular malignant diseases, such as sarcoma and carcinoma, which may present with similar clinicoradiological features, sometimes making the differential diagnosis a difficult concern. ${ }^{26}$ 
Patients with DLBCL have variable clinical courses and prognosis depending on the clinical, morphological, phenotypic and genetic parameters. The revised International Prognostic Index (R-IPI) is widely used as a predictive model in DLBCL patients of all ages and clinical stages. ${ }^{27}$ Diffuse large B-cell lymphoma can now be cured in more than $50 \%$ of patients. This is a result of improved definitions of the disease, improved diagnostic capabilities, better staging and restaging techniques, a useful prognostic index to guide therapeutic decisions, and the development of increasingly effective therapies. Positron emission tomographic scans have improved the accuracy of both staging and restaging. ${ }^{28}$ Several subtypes of diffuse large B-cell lymphoma have been identified that require specific treatment approaches. The 5 years disease free survival was reported in $53.2 \%$ patients with centroblastic and $26.9 \%$ patients with immunoblastic NHL. ${ }^{29}$ The prompt diagnosis had a critical value in allowing a proper and timely intervention and avoiding the risk of disease progression.

\section{CONCLUSION}

A case of primary DLBCL of the mandible is presented. Owing to their low frequency and to their not specific symptoms, these lesions of the mandible are often misdiagnosed. The importance of using advanced imaging techniques as well as histopathology in the diagnosis and management of intraosseous diffuse large B-cell lymphoma is discussed. This case report emphasizes that, although rare, lymphoma should be considered in the differential diagnosis.

\section{REFERENCES}

1. Mahmal L, Jabri A, Jabri L, Harif M, Quessari A, Benchakroun Y, Iraqi A, Benchekroun S. Primary non-Hodgkin's lymphoma of the mandible: apropos of three cases. Rev Stomatol Chir Maxillofac 2003;104(2):111-114.

2. Kolokotronis A, Konstantinou N, Christakis I, Papadimitriou P, Matiakis A, Zaraboukas T, Antoniades D. Localized B-cell non-Hodgkin's lymphoma of oral cavity and maxillofacial region: a clinical study. Oral Surg Oral Med Oral Pathol Oral Radiol Endod 2005;99(3):303-310.

3. Kawasaki G, Nakai M, Mizuno A, Nakamura T, Okabe H. Malignant lymphoma of the mandible: report of a case. Oral Surg Oral Med Oral Pathol Oral Radiol Endod 1997;83(3): 345-349.

4. Parrington SJ, Punnia-Moorthy A. Primary non-Hodgkin's lymphoma of the mandible presenting following tooth extraction. Br Dent J 1999;187(9):468-470.

5. Adouani A, Bouguila J, Jeblaoui Y, Ben Aicha M, Abdelali MA, Hellali M, Zitouni K, Amani L, Issam Z. B-cell lymphoma of the mandible: a case report. Clin Med Oncol 2008;2:445-450.

6. Piatelli A, Croce A, Tete S, Artese L. Primary non-Hodgkin's lymphoma of the mandible: a case report. J Oral Maxillofac Surg 1997;55(10):1162-1166.
7. Mnejja M, Hammami B, Kolsi N, Kallel S, Chakroun A, Charfeddine I, Hdiji S, Elloumi M, Ghorbel A. B-cell lymphoma of the mandible. Eur Ann Otorhinolaryngol Head Neck Dis 2010;127(5):186-188.

8. Longo F, De Maria G, Esposito P, Califano L. Primary nonHodgkin's lymphoma of the mandible: report of a case. Int J Oral Maxillofac Surg 2004;33(8):801-803.

9. Dominis M, Dzebro S, Gasparov S, Pesut A, Kusec R. Diffuse large B-cell lymphoma and its variants. Croat Med J 2002;43(5):535-540.

10. Gurbuxani S, Anastasi J, Hyjek E. Diffuse large B-cell lymphoma-more than a diffuse collection of large B cells: an entity in search of a meaningful classification. Arch Pathol Lab Med 2009;133(7):1121-1134.

11. De Paepe P, Achten R, Verhoef G, Wlodarska I, Stul M, Vanhentenrijk V, Praet M, De Wolf-Peeters C. Large cleaved and immunoblastic lymphoma may represent two distinct clinicopathologic entities within the group of diffuse large B-cell lymphomas. J Clin Oncol 2005;23(28):7060-7068.

12. Staton AD, Koff JL, Chen Q, Ayer T, Flowers CR. Nextgeneration prognostic assessment for diffuse large B-cell lymphoma. Future Oncol 2015;11(17):2443-2457.

13. Bosch-Barrera J, Arbea L, Garcia-Velloso MJ, Gil-Bazo I, Garcia-Foncillas J, Panizo C. Primary bone lymphoma of the mandible and thyroid incidentaloma identified by FDG PET/ CT: a case report. Cases J 2009;2:6384.

14. Weber AL, Rahemtullah A, Ferry JA. Hodgkin and nonHodgkin lymphoma of the head and neck: clinical, pathologic and imaging evaluation. Neuroimaging Clin N Am 2003;13(3):371-392.

15. Kemp S, Gallagher G, Kabani S, Noonan V, O’Hara C. Oral non-Hodgkin's lymphoma: review of the literature and world health organization classification with reference to 40 cases. Oral Surg Oral Med Oral Pathol Oral Radiol Endod 2008;105(2):194-201.

16. van der Waal RI, Huijgens PC, van der Valk P, van der Waal I. Characteristics of 40 primary extranodal non-Hodgkin lymphomas of the oral cavity in perspective of the new WHO classification and the international prognostic index. Int J Oral Maxillofac Surg 2005;34(4):391-395.

17. Okahata R, Shimamoto H, Marutani K, Tomita S, Nakatani A, Kishino M, Kakimoto N, Murakami S, Furukawa S. Diffuse large B-cell lymphoma of the mandible with periosteal reaction: a case report. Oral Surg Oral Med Oral Pathol Oral Radiol 2014;117(2):e228-232.

18. Bhattacharyya I, Chehal HK, Cohen DM, Al-Quran SZ. Primary diffuse large B-cell lymphoma of the oral cavity: germinal center classification. Head Neck Pathol 2010;4(3): 181-191.

19. Epstein JB, Epstein JD, Le ND, Gorsky M. Characteristics of oral and paraoral malignant lymphoma: a population-based review of 361 cases. Oral Surg Oral Med Oral Pathol Oral Radiol Endod 2001;92(5):519-525.

20. Bernaerts A, Vanhoenacker FM, Hintjens J, Chapelle K, Salgado R, De Foer B, De Schepper AM. Tumors and tumor-like lesions of the jaw: radiolucent lesions. JBR-BTR 2006;89(2):81-90.

21. Padhani AR. Dynamic contrast-enhanced MRI in clinical oncology: current status and future directions. J Magn Reson Imaging 2002;16(4):407-422.

22. Barbieri E, Cammelli S, Mauro F, Perini F, Cazzola A, Neri S, Bunkheila F, Ferrari S, Brandoli V, Zinzani P, et al. 
Primary non-Hodgkin's lymphoma of the bone: treatment and analysis of prognostic factors for stage I and II. Int J Radiat Oncol Biol Phys 2004;59(3):760-764.

23. Someya M, Sakata K, Nagakura H, Itou K, Nakata K, Oouchi A, Satoh M, Hareyama M. Three cases of diffuse large B-cell lymphoma of the mandible treated with radiotherapy and chemotherapy. Radiat Med 2005;23(4):296-302.

24. Horning SJ, Weller E, Kim K, Earle JD, O'Connell MJ, Habermann TM, GlickJH.Chemotherapy with or without radiotherapy in limited-stage diffuse aggressive non-Hodgkin's lymphoma: eastern cooperative oncology group study 1484 J Clin Oncol 2004;22(15):3032-3038.

25. Hamilton A, Gallipoli P, Nicholson E, Holyoake TL. Targeted therapy in haematological malignancies. J Pathol 2010;220(4):404-418.
26. Djavanmardi L, Oprean N, Alantar A, Bousetta K, Princ G. Malignant non-Hodgkin's lymphoma (NHL) of the jaws: a review of 16 cases. J Craniomaxillofac Surg 2008;36(7):410-414.

27. Sehn LH, Berry B,Chhanabhai M, Fitzgerald C, GillK,Hoskins $\mathrm{P}$, Klasa R, Savage KJ, Shenkier T, Sutherland J, et al. The revised International Prognostic Index (R-IPI) is a better predictor of outcome than the standard IPI for patients with diffuse large B-cell lymphoma treated with R-CHOP. Blood 2007;109(5):1857-1861.

28. Armitage JO. My treatment approach to patients with diffuse large B-cell lymphoma. Mayo Clin Proc 2012;87(2):161-171.

29. Zhang Y, Wang J, Sui X, Li Y, Lu K, Fang X, Jiang Y, Wang X. Prognostic and clinicopathological value of survivin in diffuse large B-cell lymphoma: a meta-analysis. Med (Baltimore) 2015;94(36):e1432. 